\title{
Differentially-expressed genes identified by suppression subtractive hybridization in the bone marrow hematopoietic stem cells of patients with psoriasis
}

\author{
ZHENYING ZHANG ${ }^{1,2}$, ZHEN YU $^{3}$, PAN TIAN ${ }^{1}$, SUCHUN HOU ${ }^{2}$, \\ SHIXIN HAN ${ }^{1}$, XUEJING TAN ${ }^{1}$, YONGJUN PIAO ${ }^{1}$ and XIAOMING LIU ${ }^{1,2}$ \\ ${ }^{1}$ Department of Dermatology, The First Affiliated Hospital of Dalian Medical University, Dalian, Liaoning 116023; \\ ${ }^{2}$ Department of Dermatology, Hong Kong University-Shenzhen Hospital, Shenzhen, Guangdong 518053; \\ ${ }^{3}$ Dalian Dermatosis Hospital, Dalian, Liaoning, P.R. China
}

Received July 6, 2013; Accepted February 24, 2014

DOI: $10.3892 / \mathrm{mmr} .2014 .2203$

\begin{abstract}
Psoriasis is a T cell-mediated, chronic, relapsing and inflammatory cutaneous disorder. The dysfunctional activity of $\mathrm{T}$ cells in patients with psoriasis is attributed to bone marrow hematopoietic stem cells (BMHSCs). To understand the pathogenic roles of BMHSCs in psoriasis, a differential gene expression analysis was performed using suppression subtractive hybridization of the BMHSCs from a patient with psoriasis and a healthy control. Using a cDNA array dot blot screening to screen 600 genes from forward- and reverse-subtracted cDNA libraries, 17 differentially-expressed sequence tags (ESTs) were identified. The genes within the ESTs were observed to be the homologs of genes that are involved in various cellular processes, including hormone signaling, RNA catabolism, protein ADP DNA base melting, transcriptional regulation, cell cycle regulation and metabolism. CD45, which was overexpressed in the psoriatic BMHSCs, was further analyzed using relative quantitative polymerase chain reaction. In addition, the levels of CD45 in the peripheral blood cells (PBCs) of the patients with psoriasis were markedly increased and closely associated with disease severity. An abnormality of hematopoietic progenitor cells, e.g., CD45 overexpression, may be transferred to PBCs via hematopoiesis, and may account for the psoriasis-inducing properties of activated $\mathrm{T}$ cells.
\end{abstract}

Correspondence to: Professor Xiaoming Liu, Department of Dermatology, Hong Kong University-Shenzhen Hospital, No. 1 Haiyuan 1 Road, Futian, Shenzhen, Guangdong 518053, P.R. China E-mail: 1xmdl_1956@126.com

Professor Shixin Han, Department of Dermatology, The First Affiliated Hospital of Dalian Medical University, No. 222 Zhongshan Road, Dalian, Liaoning 116023, P.R. China

E-mail: 15541192291@126.com

Key words: psoriasis, bone marrow hematopoietic stem cells, CD45, differentially-expressed genes, suppression subtractive hybridization

\section{Introduction}

Psoriasis is a T cell-mediated, chronic, inflammatory and hyperproliferative cutaneous disorder that affects $\sim 2 \%$ of the general population. Activated $\mathrm{T}$ cells are found in psoriatic plaques and in the circulation, and have been shown to set off a series of cellular and molecular reactions resulting in the creation of psoriatic lesions (1-3). Reagents that inhibit T-cell activation or function, and that have been shown to have efficacy in the treatment of psoriasis include specific immunosuppressive agents, immunomodulatory drugs, fusion proteins that block T-cell activation or the anergizing of $\mathrm{T}$ cells, cytokines and biologics that inhibit T-cell migration (4-8). However, recurrence or exacerbation often occurs following disease resolution when treatment with these agents is suddenly halted, which indicates that T-cell activation is not effectively blocked. It is believed that pathogenic $\mathrm{T}$ cells are activated in the periphery by a variety of infectious and non-infectious exogenous and endogenous factors (1). However, there is evidence that intrinsic factors play more important roles than extrinsic factors in the pathogenesis of psoriasis $(9,10)$. These intrinsic factors may be involved in spontaneous T-cell activation or proliferation, the regulation of cytokine production pathways, hematopoietic cell development, and T-cell development in the thymus (11).

In humans, bone marrow-derived $\mathrm{T}$-cell progenitors express cluster of differentiation (CD)34 and CD45 (12). These hematopoietic progenitor cells from the bone marrow travel through the blood to seed the thymus, attracted by chemokines, including chemokine (C-C motif) ligand 25 (13). The CD4/CD8-double-negative (DN) population contains the early thymic progenitor cells in the thymus, and the DN1 population is home to the earliest thymocyte progenitors at the corticomedullary junction. The outward migration of these cells to the cortex in response to specific chemokines, including chemokine (C-X-C motif) ligand 12, is accompanied by their differentiation into DN2 and DN3 cells (14). Differentiation into DN4 cells and subsequently, into CD4/CD8-double-positive (DP) cells, occurs along with the inward migration of the cells from the cortex to the medulla, where selection and maturation into 
CD4 or CD8 single-positive (SP) T cells takes place. Having escaped negative selection, the positively-selected thymocytes mature into naive $\mathrm{T}$ cells and leave the thymus to enter the peripheral circulation (15).

Several observations indicate a pathogenic role for bone marrow hematopoietic stem cells (BMHSCs) in psoriasis. Firstly, Zhang et al reported that in vitro-differentiated $\mathrm{T}$ cells from bone marrow $\mathrm{CD} 34^{+}$progenitor cells of patients with psoriasis are functionally similar to the circulating $\mathrm{T}$ cells of these patients. The differentiated $\mathrm{T}$ cells from the studied patients with psoriasis showed higher proliferation and a marked capacity to secret Th1 cytokines in response to streptococcal superantigen, and to induce the overexpression of C-myc and Ki67, but not B-cell lymphoma-extra large (Bcl-XL), in keratinocytes (16). Secondly, a study of high-proliferative potential colony-forming cells (HPP-CFCs) isolated from patients with psoriasis revealed that the bone marrow of patients with psoriasis is pathogenic by its very nature, and is deficient for bone marrow hematopoietic cells (17). Thirdly, runt-related transcription factor 1 (RUNX1), with a restricted expression pattern, is essential for hematopoietic cell development (18). Furthermore, the genetic defect that lies between the sodium-hydrogen antiporter 3 regulator 1 and $\mathrm{N}$-acetyltransferase 9 genes on chromosome $17 \mathrm{q} 25$ and which results in the loss of a $R U N X 1$ binding site may be involved in psoriasis (19). Finally, allogeneic bone marrow transplantation (BMT) provides evidence to support the hematopoietic basis of psoriasis susceptibility. Reconstituting T-cell populations by allogeneic BMT into psoriatic individuals results in long-term remission or amelioration of the disease $(20,21)$. By contrast, BMT from psoriatic donors into patients with no history of psoriasis results in development of psoriasis (22). Therefore, bone marrow hematopoietic precursor cells with abnormal expression of specific genes are believed to be responsible for the $\mathrm{T}$ cell-related immune dysregulation in psoriasis.

To test this hypothesis, suppression subtractive hybridization (SSH) was performed on the BMHSCs of a patient with psoriasis and a healthy control. In the current study, 17 differentially-expressed sequence tags (ESTs), including the CD45 gene were obtained from the forward- and reverse-SSH libraries. Since CD45 is known to be an important regulator of signal transduction in the process of T-cell development and activation (23), the CD45 expression levels in the bone marrow-derived hematopoietic progenitors and peripheral blood cells (PBCs) of 20 patients with psoriasis and 10 healthy subjects were analyzed by quantitative polymerase chain reaction (qPCR) and flow cytometry.

\section{Materials and methods}

Participants. A total of 20 patients with psoriasis vulgaris (16 males and 4 females; median age, 36.8 years; range, 20-58 years) participated in the study. Eligible patients were those diagnosed with plaque psoriasis lasting for at least 6 months, a family history of psoriasis, at least $10 \%$ of the total body surface area affected, and a mean psoriasis area and severity index (PASI) score of $16.87 \pm 1.26$ [mean \pm standard deviation (SD)]. The control group consisted of 10 age- and sex-matched healthy individuals. None of the patients or control subjects had received topical or oral medications in the 6 months prior to the study. Among the subjects, the bone marrow samples of a female patient with psoriasis and a healthy control were used to construct a subtractive cDNA library. Bone marrow and peripheral blood samples were collected from all participants and used to check the CD45 expression levels in the BMHSCs and PBCs. This study was approved by the Ethics Committee of the First Affiliated Hospital of Dalian Medical University. All participants were fully aware of the purpose of the study and provided written informed consent.

Isolation of $\mathrm{CD} 4^{+}$cells from bone marrow. From each subject, $10 \mathrm{ml}$ of bone marrow aspirate was drawn into tubes containing sodium heparin. Bone marrow mononuclear cells (BMMNCs) were isolated from bone marrow aspirates by density gradient centrifugation in Ficoll1077 (Sigma Chemical Co., St. Louis, MO, USA) followed by lysis of the remaining erythrocytes with $0.15 \mathrm{M}$ Tris-ammonium chloride. $\mathrm{CD}^{+} 4^{+}$cells were isolated from BMMNCs with magnetic beads conjugated to anti-human CD34 antibodies and anti-idiotype antibodies (Dynal Biotech, Milwaukee, Wisconsin, USA) according to the manufacturer's instructions. The purity of the CD34 cells and the percentage of remaining $\mathrm{CD} 1 \mathrm{a} \mathrm{CD} 3$ cells were evaluated by flow cytometry with fluorescein isothiocyanate (FITC)-labeled anti-CD34 antibody, phycoerythrin (PE)-conjugated anti-CDla antibody and FITC-conjugated anti-CD3 antibody (BD Pharmingen, Tokyo, Japan).

Subtractive cDNA library construction. Total RNA was extracted with the TRIzol Reagent kit (Invitrogen Life Technologies, Carlsbad, CA, USA), and mRNA was purified with the Dynabeads mRNA Purification kit (Dynal Biotech, Oslo, Norway), according to the manufacturers' instructions. cDNA was synthesized and amplified using the SMART PCR cDNA synthesis kit (BD Biosciences-Clontech, Palo Alto, CA, USA). In the current study, $2 \mathrm{mg}$ total RNA was used to generate each cDNA population for use in the subtraction procedure. The manufacturer's recommendations were used throughout the cDNA synthesis procedure. Differentially-expressed genes were identified using the Clontech PCR-Select cDNA Subtraction kit (BD Biosciences-Clontech). In brief, the SMART cDNA of the patient and healthy control were subjected to RsaI digestion, adaptor ligation, two rounds of subtractive hybridization and subsequent PCR amplifications. The forward-subtracted cDNA, i.e., cDNA from the patient as the tester and cDNA from the healthy control as the driver, and the reverse-subtracted cDNA, i.e., cDNA from the healthy control as the tester and cDNA from yeast as the driver, were inserted into the pMD-T18 vector (Takara, Tokyo, Japan) and transformed into Escherichia coli DH5a. The forward- and reverse-subtracted cDNA plasmid libraries were constructed and individual colonies that showed the presence of inserted DNA were randomly picked and analyzed.

Screening for differentially-expressed genes by cDNA array dot blot screening. From the two subtracted cDNA libraries, 600 recombinant bacterial clones were picked by blue-white selection on plates. The white colonies were incubated at $37^{\circ} \mathrm{C}$ 
Table I. Primers and Taqman probe.

\begin{tabular}{cll}
\hline Name & Primers and Taqman probe & \multicolumn{1}{c}{ Primers for qPCR $\left(5^{\prime} \rightarrow 3^{\prime}\right)$} \\
\hline CD45 & \multicolumn{1}{c}{ F } & ctgccagctgaggtgcaa \\
& R & tgcactgtcggttccetact \\
& Taqman probe & Fam-aaaccagtcgagtcccaaacctcaa-Tamra \\
\hline
\end{tabular}

qPCR, quantitative polymerase chain reaction; CD45, cluster of differentiation 45 .

for $12 \mathrm{~h}$ in Eppendorf tubes in $1 \mathrm{ml}$ Luria-Bertani (LB) broth that contained $50 \mu \mathrm{g} / \mathrm{ml}$ ampicillin. Each bacterium in the LB culture was amplified in a $50 \mu \mathrm{l}$ PCR system using the nested PCR primers: 1, 5'-TCGAGCGGCCGCCCGGGCAGGT-3'; and 2R, 5'-AGCGTGGTCGCGGCCGAGGT-3'. PCR was performed as follows: $95^{\circ} \mathrm{C}$ for $2 \mathrm{~min}, 35$ cycles of $95^{\circ} \mathrm{C}$ for $30 \mathrm{sec}, 62^{\circ} \mathrm{C}$ for $45 \mathrm{sec}$ and $72^{\circ} \mathrm{C}$ for $1 \mathrm{~min}$, and $72^{\circ} \mathrm{C}$ for $6 \mathrm{~min}$. The PCR product was confirmed on a $2 \%$ agarose gel and the remainder was used for differential screening.

In total, 571 clones with cDNA inserts from two subtractive libraries were selected randomly for cDNA array dot blot screening. Briefly, the PCR product $(5 \mu \mathrm{l})$ was denatured with an equal volume of $0.5 \mathrm{M} \mathrm{NaOH}$, and $1.5 \mu \mathrm{l}$ of this mixture was spotted onto two identical nitrocellulose membranes (Roche, Basel, Switzerland). The two identical blots were UV cross-linked and hybridized with digoxigenin (DIG)-labeled forward- and reverse-subtracted cDNA probes, which were prepared using DIG High Prime DNA Labeling and Detection Starter kit II (Roche). Hybrids were detected using an alkaline phosphatase-conjugated anti-DIG antibody (1:1,000 dilution). The chemiluminescent signals were generated by treating the membranes with $1 \%$ CSPD, and recorded on an X-ray film (Fuji Biomax MR film; Fujifilm, Minato, Tokyo, Japan).

Sequencing and sequence analysis. In total, 144 clones identified by differential screening of the two SSH libraries were sequenced with the universal M13 sequencing primer using an automatic DNA sequencer (ABI Applied Biosystems Model 3730). All inserted sequences were queried for similarity in the National Center for Biotechnology Information (NCBI) database using the BLASTX program (http://www.ncbi.nlm.nih.gov/BLAST).

Relative quantification of CD45 mRNA expression in BMHSCs by $q P C R$. The CD45 EST was selected for further analysis by qPCR. The primers and TaqMan probe for the target gene were designed using Primer Select in DNASTAR software (Lasergene, Madison, WI, USA) and are listed in Table I. The levels of RNA ( $2 \mu \mathrm{g}$ of each) were assayed in the BMHSCs of 20 patients and 10 healthy controls using the SYBR ExScript RT-PCR kit (Takara). The amplification conditions were optimized for the ABI PRISM-7500 instrument (Applied Biosystems). The cycling conditions using TaqMan probe detection were $95^{\circ} \mathrm{C}$ for $2 \mathrm{~min}$ and 40 cycles of $95^{\circ} \mathrm{C}$ for $10 \mathrm{sec}$, $61^{\circ} \mathrm{C}$ for $10 \mathrm{sec}$ and $72^{\circ} \mathrm{C}$ for $40 \mathrm{sec}$. The $\beta$-actin gene was selected as the endogenous control. Relative quantification of target gene expression was evaluated using the comparative cycle threshold (CT) method, as previously described (24). The $\triangle \mathrm{CT}$ value was determined by subtracting the target $\mathrm{CT}$ of each sample from its respective $\beta$-actin CT value. Calculation of $\Delta \Delta \mathrm{CT}$ involved using the healthy control sample $\Delta \mathrm{CT}$ value as an arbitrary constant to subtract from the $\Delta \mathrm{CT}$ values of the patient sample. Differences in the expression of target genes were determined by calculating $2^{-\Delta \Delta C T}$.

Flow cytometric analysis of CD45 expression in PBCs. For immunofluorescence staining, $1 \times 10^{6}$ cells were incubated with PerCP-CD45 monoclonal antibodies for $20 \mathrm{~min}$ at $4^{\circ} \mathrm{C}$. Following two washes with phosphate-buffered saline that contained $5 \%$ fetal calf serum, the labeled cells were analyzed by FACSCalibur using the CELLQuest software (all BD Biosciences-Clontech).

Statistical analysis. Data are expressed as the mean $\pm \mathrm{SD}$, unless indicated otherwise. Comparisons of patients with psoriasis and healthy control subjects were performed with an unmatched t-test. Spearman's non-parameter correlation analysis was used to examine the correlation between disease severity and CD45 expression levels in the BMHSCs and PBCs. $\mathrm{P}<0.05$ was considered to indicate a statistically significant difference.

\section{Results}

Generation and identification of differentially-expressed cDNA fragments. Using nested PCR primers 1 and $2 \mathrm{R}$, 300 recombinant bacteria clones were amplified from the forward-SSH library, and 300 clones were amplified from the reverse-SSH library. Only clones that had cDNA inserts that carried adaptor 1 and adaptor $2 \mathrm{R}$ on the two ends were amplified. The inserts ranged in size between 200 and 1,000 bp, as assessed by agarose gel electrophoresis. Overall, 284/300 clones from the forward-SSH library and 287/300 clones from the reverse-SSH library contained inserted fragments, and these were subjected to further analysis. The remaining clones were false-positives. From the two SSH libraries, 571 clones with cDNA insert sizes that ranged in size between 200 and 1,000 bp were selected to be undergo cDNA array dot blot screening. Of these clones, 74 positive clones from the forward-SSH library showed marked signals using the forward-subtracted probe compared with using the reverse-subtracted probe, and 70 clones from the reverse-SSH library showed marked signals with the reverse-subtracted probe compared with the forward-subtracted probe. These 144 positive clones were selected for further sequencing. 
Table II. Gene fragments preferentially expressed in the HSCs of a patient with psoriasis.

\begin{tabular}{|c|c|c|c|c|c|}
\hline $\begin{array}{l}\text { Clone } \\
\text { number }\end{array}$ & $\begin{array}{l}\text { Fragment } \\
\text { sizes, bp }\end{array}$ & $\begin{array}{l}\text { Homologous } \\
\text { gene }\end{array}$ & $\begin{array}{l}\text { Genotype } \\
\text { ID }\end{array}$ & $\begin{array}{c}\text { Homology, } \\
\%\end{array}$ & Gene activity \\
\hline $6046-0259$ & 384 & MMP-1 & 4312 & 47 & $\begin{array}{l}\text { Matrix metalloproteinase, degrade all components of } \\
\text { extracellular matrix }\end{array}$ \\
\hline 6046-0292 & 410 & $\mathrm{APOH}$ & 350 & 42 & Apolipoprotein \\
\hline $6046-0288$ & 404 & $\mathrm{IFN} \gamma$ & 3458 & 100 & $\begin{array}{l}\text { IFN, a soluble cytokine with antiviral, immunoregulatory } \\
\text { and anti-tumor properties and is a potent activator of } \\
\text { macrophages }\end{array}$ \\
\hline $1067-0526$ & 367 & CD45 & 5788 & 100 & $\begin{array}{l}\text { Protein tyrosine phosphatase, an essential regulator of T- } \\
\text { and B-cell antigen receptor signaling }\end{array}$ \\
\hline $1067-0519$ & 400 & SAE1 & 10055 & 100 & $\begin{array}{l}\text { As a SUMO-activating enzyme for the sumoylation of } \\
\text { proteins }\end{array}$ \\
\hline $1067-0533$ & 439 & CA3 & 761 & 87 & $\begin{array}{l}\text { Carbonic anhydrase isozymes, catalyze the reversible } \\
\text { hydration of carbon dioxide }\end{array}$ \\
\hline $1067-0469$ & 383 & Ribonuclease T2 & 8635 & 78 & $\begin{array}{l}\text { Associated with human malignancies and chromosomal } \\
\text { rearrangement }\end{array}$ \\
\hline $1067-0529$ & 485 & CD99 & 83692 & 55 & An adhesion molecule during leukocyte extravasation \\
\hline $1067-0535$ & 457 & MT-ND4 & 4538 & 94 & $\begin{array}{l}\text { Oxidation-reduction enzyme, involved in oxidative } \\
\text { phosphorylation }\end{array}$ \\
\hline
\end{tabular}

HSCs, hematopoietic stem cells; MMP-1, matrix metalloproteinase 1; APOH, apolipoprotein H; IFN $\gamma$, interferon $\gamma$; CD45, cluster of differentiation 45; SAE1, SUMO-activating enzyme subunit 1; CA3, carbonic anhydrase 3; MT-ND4, NADH dehydrogenase subunit 4.

Table III. Gene fragments preferentially expressed in HSCs of a healthy control.

\begin{tabular}{|c|c|c|c|c|c|}
\hline $\begin{array}{l}\text { Clone } \\
\text { number }\end{array}$ & $\begin{array}{l}\text { Fragment } \\
\text { sizes, bp }\end{array}$ & $\begin{array}{l}\text { Homologous } \\
\text { gene }\end{array}$ & $\begin{array}{l}\text { Genotype } \\
\text { ID }\end{array}$ & $\begin{array}{c}\text { Homology, } \\
\%\end{array}$ & Gene activity \\
\hline $6045-0252$ & 430 & CYP3A43 & 64816 & 72 & $\begin{array}{l}\text { Mono oxygenases which catalyze many reactions } \\
\text { involved in drug metabolism and synthesis of } \\
\text { cholesterol, steroids and other lipids }\end{array}$ \\
\hline $6045-0264$ & 440 & ATP synthase & NULL & 92 & NULL \\
\hline $1066-0441$ & 436 & TMSB 10 & 9168 & 100 & NULL \\
\hline $1066-0547$ & 446 & RABGAP1L & 9910 & 91 & G-protein modulator \\
\hline $1066-0459$ & 500 & ART3 & 419 & 73 & $\begin{array}{l}\text { ADP-ribosylation is a reversible posttranslational } \\
\text { modification used to regulate protein function }\end{array}$ \\
\hline $1066-0450$ & 356 & Squalene epoxidase & 29230 & 72 & Enzyme that catalyzes sterol biosyntesis \\
\hline $1066-0453$ & 421 & RAPH1 & 65059 & 63 & $\begin{array}{l}\text { Regulator of transmembrane protein, involve-d } \\
\text { in signal transduction }\end{array}$ \\
\hline $1066-0432$ & 358 & NDUFB5 & 4711 & 52 & $\begin{array}{l}\text { This protein has NADH dehydrogenase activity } \\
\text { and oxidoreductase activity }\end{array}$ \\
\hline
\end{tabular}

HSCs, hematopoietic stem cells; ATP, adenosine triphosphate; CYP3A43, cytochrome P450 3A43; TMSB 10, thymosin $\beta 10$; RABGAP1L, RAB GTPase activating protein 1-like; ART3, ecto-ADP-ribosyltransferase 3; RAPH1, ras-associated and pleckstrin homology domains-containing protein 1; NDUFB5, NADH dehydrogenase (ubiquinone) $1 \beta$ subcomplex 5.

Sequence analysis of differentially-expressed genes. A total of 144 clones were sequenced and compared with NCBI proteins using BLASTX. Significant similarities to known genes were identified for 9/74 clones (Table II) in the forward-SSH library and 8/70 clones (Table III) in the reverse-SSH library; the remaining clones showed low-level similarity to known genes or represented novel genes. The clones that showed marked similarity to known proteins were linked to: i) Metabolism; ii) cell wall biogenesis and remodeling; iii) signal transduction; and iv) stress. Other clones had weaker similarity with known proteins or represented hypothetical proteins; their roles were not confirmed. 
Table IV. Relative abundance of CD45 gene in HSCs, as determined by qPCR.

\begin{tabular}{|c|c|c|c|c|c|}
\hline \multirow[b]{2}{*}{ Group } & \multirow[b]{2}{*}{$\mathrm{CD} 45, \mathrm{CT}$} & \multirow[b]{2}{*}{$\beta$-actin, CT } & \multicolumn{3}{|c|}{ CD45 } \\
\hline & & & $\Delta \mathrm{CT}$ & $\Delta \Delta \mathrm{CT}$ & $2-\Delta \Delta \mathrm{CT}$ \\
\hline Patients & $19.06 \pm 0.58$ & $21.40 \pm 0.66$ & $-2.28 \pm 1.13$ & $-3.53 \pm 1.31$ & $11.55^{\mathrm{a}}$ \\
\hline Normal & $21.42 \pm 0.53$ & $20.17 \pm 0.20$ & $0.25 \pm 0.53$ & $0.00 \pm 0.53$ & 1 \\
\hline
\end{tabular}

${ }^{a} \mathrm{P}<0.001$ vs. normal control. qPCR, quantitative polymerase chain reaction; HSCs, hematopoietic stem cells; CD45, cluster of differentiation 45 .

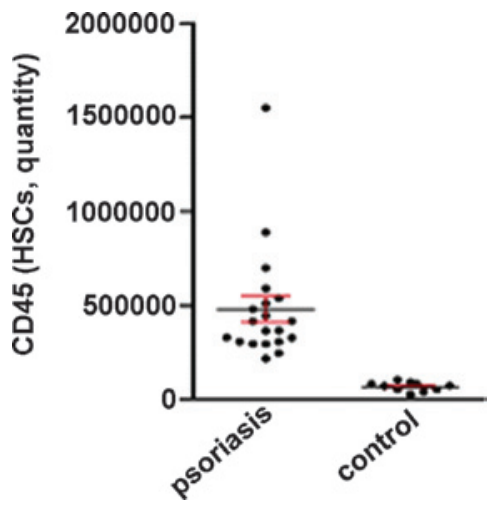

Figure 1. Marked expression of CD45 in the BMHSCs of 20 patients with psoriasis compared with 10 healthy control subjects. BMHSCs, bone marrow hematopoietic stem cells; CD45, cluster of differentiation 45.

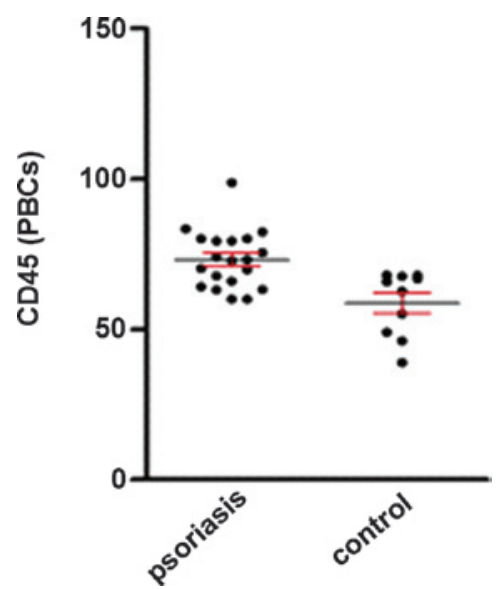

Figure 2. High expression level of CD45 in the PBCs of 20 patients with psoriasis $(73.17 \pm 2.14 \%)$ compared with 10 healthy control subjects $(58.81 \pm 3.40 \%)$. PBCs, peripheral blood cells; CD45, cluster of differentiation 45.

Marked expression of CD45 in the BMHSCs of a patient with psoriasis. To confirm the reliability of $\mathrm{SHH}$ and dot blot screening, the expression levels of CD45 were examined in the BMHSCs of the 20 patients with psoriasis and the 10 healthy control subjects using relative qPCR. Following amplification, the $\mathrm{CT}, \Delta \Delta \mathrm{CT}, \Delta \Delta \mathrm{CT}$ and $2^{-\Delta \Delta \mathrm{CT}}$ values were calculated (Table IV). Notably, the expression level of CD45 was 11.55-fold higher in the BMHSCs of the patients with psoriasis compared with the healthy controls $(\mathrm{P}<0.001 ;$ Fig. 1$)$.

High expression level of CD45 in the PBCs of patients with psoriasis. As shown in Fig. 2, the expression level of CD45 in

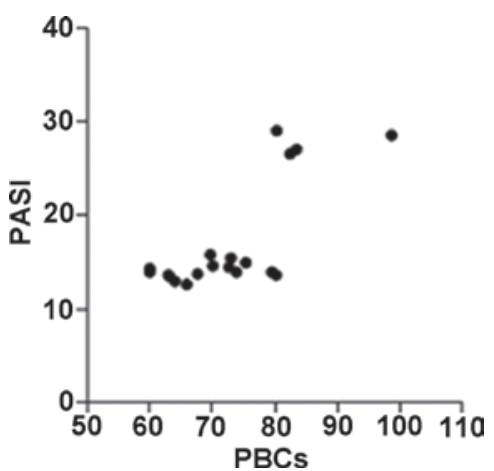

Figure 3. Correlation between CD45 level in PBCs and PASI score of patients with psoriasis $(\mathrm{r}=0.615$; $\mathrm{P}=0.004)$. $\mathrm{PBCs}$, peripheral blood cells; PASI, psoriasis area and severity index; CD45, cluster of differentiation 45.

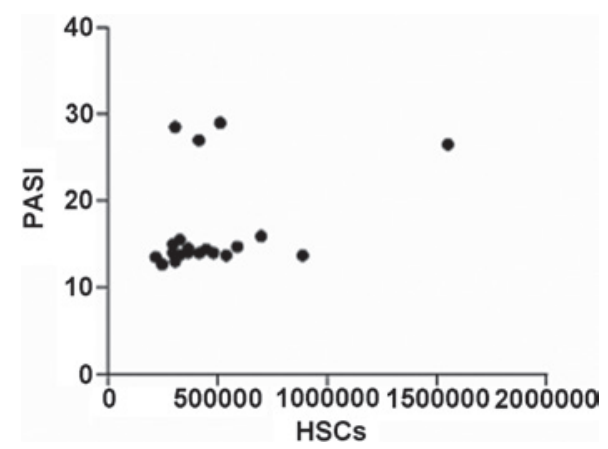

Figure 4. Association between CD45 level in BMHSCs and PASI score of patients with psoriasis. $(\mathrm{r}=0.321 ; \mathrm{P}=0.168)$. BMHSCs, bone marrow hematopoietic stem cells; PASI, psoriasis area and severity index; CD45, cluster of differentiation 45 .

the PBCs was markedly higher in the patients with psoriasis $(73.17 \pm 2.14 \%)$ compared with the healthy control subjects $(58.81 \pm 3.40 \%)(\mathrm{P}<0.05)$.

Correlation between disease severity and CD45 expression levels in BMHSCs and PBCs. The CD45 expression levels in the PBCs of the patients with psoriasis were significantly correlated with their PASI scores $(\mathrm{r}=0.615 ; \mathrm{P}=0.004)$, whereas the CD45 expression levels in the BMHSCs were not correlated with the PASI scores $(\mathrm{r}=0.321 ; \mathrm{P}=0.168)$ (Figs. 3 and 4$)$.

\section{Discussion}

Investigations of differential gene expression in the BMHSCs of patients with psoriasis and healthy controls may lead to the 
discovery of candidate genes for the pathogenicity of psoriasis. In the present study, 17 differentially-expressed genes were identified by suppression subtractive hybridization. These genes were sorted into the broad functional categories of hormone signaling, RNA catabolism, protein ADP DNA base melting, transcriptional regulation, cell cycle regulation and metabolism. This diversity of genes indicates that a complex series of molecular mechanisms is involved in the pathogenesis of psoriasis.

Of the 17 differentially-expressed genes detected in the BMHSCs of the patient with psoriasis and a healthy control in the present investigation, clone 1067-0526, which includes the CD45 EST, was focused upon. CD45, a leukocyte-common antigen, is a transmembrane protein tyrosine phosphatase that is specifically expressed on all nucleated hematopoietic cells, from stem cells to memory cells. In humans, bone marrow-derived T-cell progenitors have been shown to express CD34 and CD45 (12), and CD45 is an important regulator of signal transduction at multiple stages of T-cell development from the early precursors (23). The expression of CD45 in hematopoietic cells is essential for early thymocyte development, and mice and humans lacking CD45 expression are severely immunodeficient (25). In CD45-deficient mice, there is partial blockage of DN1 and DN3 progression and an almost complete blockage of DP development to SP cells, attributed to an increased threshold of T-cell receptor (TCR) $\beta$, pre-TCR and TCR signaling, respectively. A major reduction in the numbers of mature SP T cells is consequently found in the periphery of CD45-deficient mice $(23,26)$. In the present study, CD45 showed the highest repeat frequency among the forward-SSH sequences, and was expressed 11.55-fold higher in the BMHSCs of the patients with psoriasis compared with those of the controls. Previous studies have indicated that the BMHSCs from patients with chronic plaque-type psoriasis differentiate into mature $\mathrm{T}$ cells with normal percentages of SP cells, albeit with increased proliferative activity (16). Therefore, the overexpressed CD45 in psoriatic BMHSCs is hypothesized to act as a positive regulator of signals delivered via TCR expression during early T-cell development, so that the proliferative ability, but not the absolute number of mature SP T cells is markedly increased, further involving the pathogenesis of psoriasis.

CD45 expression on mature hemocytes is critical for the regulation of immune function, as it functions positively to regulate T-lymphocyte activation (27). An early study demonstrated that a CD45-deficient $\mathrm{CD} 4^{+} \mathrm{T}$-cell clone lost reactivity to its specific antigen and the ability to proliferate in response to a mitogenic signal and anti-CD3 cross-linking, while it retained the ability to proliferate in response to interleukin 2 (28). This implied that CD45 was important in transducing the signal initiated by antigen binding to the TCR. Subsequent studies confirmed this observation. A CD ${ }^{+} / \mathrm{CD} 45^{-}$deficient T-cell clone that lost the abilities to cytolyze its appropriate target cells and to produce cytokines in response to the antigen was observed (29). However, transfection with CD45 cDNA restored the activation response to TCR ligation (30). In addition, CD45 may regulate cytokine production and responses to cytokines in other hematopoietic cells. Previous studies have shown that CD45 is required for interferon (IFN)- $\alpha$ and IFN- $\gamma$ production by dendritic cells and NK cells following stimulation via the immunoglobulin Fc or major histocompatibility complex-binding receptors $(31,32)$.

Compared with the healthy controls, the expression levels of CD45 in the PBCs of the patients with psoriasis were markedly higher in the current study. The CD45 levels in the PBCs were observed to be closely correlated with the PASI, which is indicative of psoriasis severity. Dawes et al produced transgenic mice that expressed an altered level of CD45 and found that the total level of CD45 expressed was crucial for normal TCR signaling, lymphocyte proliferation and the production of cytokines, including IFN- $\gamma$ and tumor necrosis factor (TNF)- $\alpha$ (33). Therefore, it is likely that increased CD45 levels in PBCs are responsible for the abnormal immune state of patients with psoriasis, which includes increased lymphocyte proliferation activity and high levels of IFN- $\gamma$ and TNF- $\alpha$ production, which further exacerbate psoriasis.

Taken together, the current data indicate that the abnormalities of hematopoietic progenitor cells that result in the overexpression of CD45 may lead to similar abnormalities in the PBCs via hematopoiesis. The increased level of CD45 in PBCs, particularly on T lymphocytes, may account for the psoriatic features, including the increased proliferative activity and elevated secretion of Th1 cytokines.

In the present study, increased levels of IFN- $\gamma$ were observed in the BMHSCs of patients with psoriasis, which is in accordance with the changes in IFN $-\gamma$ previously observed in the sera of patients with psoriasis (34). It is generally hypothesized that serum IFN- $\gamma$ plays an important role in the pathogenesis of psoriasis (35). Serum cytokine concentrations are altered by several processes, including the production, deposition, degradation and elimination of these molecules. Furthermore, tissue sources of cytokine production other than circulating $\mathrm{T}$ cells may exist. The origin of the IFN- $\gamma$ in the sera of patients with psoriasis is not clear (36). In future studies of psoriasis, further investigation is required to determine whether the increased level of IFN- $\gamma$ in BMHSCs contributes to the increased serum IFN- $\gamma$ level, and whether this elevation is conferred upon peripheral $\mathrm{T}$ cells via hematopoiesis.

Other genes that encode proteins that affect hormone signaling, RNA catabolism, protein ADP DNA base melting, transcriptional regulation, cell cycle regulation and metabolism were identified in the present study. However, as there are few relevant studies on these genes in BMHSCs or in relation to psoriasis, it is difficult to assign specific roles to these genes in the development of psoriasis. Future studies that investigate these gene expression changes may be beneficial in characterizing the dysfunctional T cells derived from psoriatic BMHSCs.

While several genes, including p15, p21, RUNX1, HLA-C, and $P R K C B$ were previously found to be overexpressed in the HSCs of patients with psoriasis $(37,38)$, these genes were not identified in the present study. The reasons for this could be that earlier investigations extracted mRNA from different samples than those employed in the present investigation. Given the different geographic origins of each sample, there are likely to be innate differences in the genetic structures of the two subjects, which may be reflected in their protein profiles. In 
addition, these differences may reflect a bias in choosing gene clones of interest or technical limitations associated with the methodologies employed.

The present data indicate that the abnormal expression of genes, such as the augmented expression of CD45 in the BMHSCs, may induce the production of pathogenic $\mathrm{T}$ lymphocytes that play a role in the progression of psoriasis. The present findings may have substantial implications for our understanding of the pathophysiology of psoriasis and the development of novel treatment strategies.

\section{Acknowledgements}

The study was supported by a grant from the National Natural Science Foundation of China (grant nos. 30872271 and 81171507).

\section{References}

1. Nickoloff BJ: The immunologic and genetic basis of psoriasis. Arch Dermatol 135: 1104-1110, 2000.

2. Sabat R, Philipp S, Höflich C, et al: Immunopathogenesis of psoriasis. Exp Dermatol 16: 779-798, 2007.

3. van Lingen R G, van de Kerkhof P C, de Jong E M, et al: Reduced CD26 bright expression of peripheral blood CD8+ T-cell subsets in psoriatic patients. Exp Dermatol 17: 343-348, 2008.

4. Berth-Jones J: The use of ciclosporin in psoriasis. J Dermatolog Treat 16: 258-277, 2005.

5. Krueger JG, Wolfe JT, Nabeya RT, et al: Successful ultraviolet $B$ treatment of psoriasis is accompanied by a reversal of keratinocyte pathology and by selective depletion of intraepidermal T cells. J Exp Med 182: 2057-2068, 1995.

6. Gottlieb S L, Gilleaudeau P, Johnson R, et al: Response of psoriasis to a lymphocyte-selective toxin (DAB389IL-2) suggests a primary immune, but not keratinocyte, pathogenic basis. Nat Med 1: 442-447, 1995.

7. Abrams J R, Kelley S L, Hayes E, et al: Blockade of T lymphocyte costimulation with cytotoxic T lymphocyte-associated antigen 4-immunoglobulin (CTLA4Ig) reverses the cellular pathology of psoriatic plaques, including the activation of keratinocytes, dendritic cells, and endothelial cells. J Exp Med 192: 681-694, 2000.

8. Gordon KB, Papp KA, Hamilton TK, et al: Efalizumab for patients with moderate to severe plaque psoriasis: a randomized controlled trial. JAMA 290: 3073-3080, 2003.

9. Tomfohrde J, Silverman A, Barnes R, et al: Gene for familial psoriasis susceptibility mapped to the distal end of human chromosome 17q. Science 264: 1141-1145, 1994.

10. Hüffmeier U, Steffens M, Burkhardt H, et al: Evidence for susceptibility determinant(s) to psoriasis vulgaris in or near PTPN22 in German patients. J Med Genet 43: 517-522, 2006.

11. Bowcock AM: The genetics of psoriasis and autoimmunity. Annu Rev Genomics Hum Genet 6: 93-122, 2005.

12. Galić Z, Kitchen SG, Subramanian A, et al: Generation of $\mathrm{T}$ lineage cells from human embryonic stem cells in a feeder free System. Stem Cells 27: 100-107, 2009.

13. Kondo M, Weissman IL and Akashi K: Identification of clonogenic common lymphoid progenitors in mouse bone marrow. Cell 91: 661-672, 1997.

14. Petrie HT and Zúñiga-Pflücker JC: Zoned out: functional mapping of stromal signaling microenvironments in the thymus. Annu Rev Immunol 25: 649-679, 2007.

15. Petrie HT: Cell migration and the control of post-natal T-cell lymphopoiesis in the thymus. Nat Rev Immunol 3: 859-866, 2003.

16. Zhang K, Li X, Yin G, et al: Functional characterization of $\mathrm{T}$ cells differentiated in vitro from bone marrow-derived CD34 cells of psoriatic patients with family history. Exp Dermatol 19: e128-e135, 2010
17. Zhang $\mathrm{K}$, Zhang $\mathrm{R}$, Li X, et al: The mRNA expression and promoter methylation status of the p16 gene in colony-forming cells with high proliferative potential in patients with psoriasis. Clin Exp Dermatol 32: 702-708, 2007.

18. Lacaud G, Gore L, Kennedy M, et al: Runx 1 is essential for hematopoietic commitment at the hemangioblast stage of development in vitro. Blood 100: 458-466, 2002.

19. Helms C, Cao L, Krueger JG, et al: A putative RUNX1 binding site variant between SLC9A3R1 and NAT9 is associated with susceptibility to psoriasis. Nat Genet 35: 349-356, 2003.

20. Kanamori H, Tanaka M, Kawaguchi H, et al: Resolution of psoriasis following allogeneic bone marrow transplantation for chronic myelogenous leukemia: case report and review of the literature. Am J Hematol 71: 41-44, 2002.

21. Woods AC and Mant MJ: Amelioration of severe psoriasis with psoriatic arthritis for 20 years after allogeneic haematopoietic stem cell transplantation. Ann Rheum Dis 65: 697, 2006.

22. Snowden JA and Heaton DC: Development of psoriasis after syngeneic bone marrow transplant from psoriatic donor: further evidence for adoptive autoimmunity. Br J Dermatol 137: 130-132, 1997.

23. Byth KF, Conroy LA, Howlett S, et al: CD45-null transgenic mice reveal a positive regulatory role for CD45 in early thymocyte development, in the selection of CD4+CD8+thymocytes, and B cell maturation. J Exp Med 183: 1707-1718, 1996.

24. Livak KJ and Schmittgen TD: Analysis of relative gene expression data using real-time quantitative PCR and the 2(-Delta Delta C(T)). Method 25: 402-408, 2001.

25. Ward V, Hennig BJ , Hirai K, et al: Geographical distribution and disease associations of the CD45 exon $6138 \mathrm{G}$ variant. Immunogenetics 58: 235-239, 2006.

26. Kishihara K, Penninger J, Wallace VA, et al: Normal B lymphocyte development but impaired $\mathrm{T}$ cell maturation in CD45-exon6 protein tyrosine phosphatase-deficient mice. Cell 74: 143-156, 1993.

27. Hermiston ML, Xu Z and Weiss A: CD45: a critical regulator of signaling thresholds in immune cells. Annu Rev Immunol 21: $107-137,2003$.

28. Pingel JT and Thomas ML: Evidence that the leukocyte-common antigen is required for antigen-induced $\mathrm{T}$ lymphocyte proliferation. Cell 58: 1055-1065, 1989.

29. Weaver CT, Pingel JT, Nelson JO, et al: CD8+ T-cell clones dificient in the expression of the CD45 protein tyrosine phosphatase have impaired responses to T-cell receptor stimuli. Mol Cell Biol 11: 4415-4422, 1991.

30. Koretzky GA, Kohmetscher MA, Kadleck T, et al: Restoration of $\mathrm{T}$ cell receptor-mediated signal transduction by transfection of CD45 cDNA into a CD45-deficient variant of the Jurkat T cell line. J Immunol 149: 1138-1142, 1992.

31. Montoya M, Dawes R, Reid D, Lee LN, Piercy J, Borrow P, Tchilian EZ and Beverley PC: CD45 is required for type I IFN production by dendritic cells. Eur J Immunol 36: 2150-2158, 2006.

32. Shen F, Xu XL, Graf LH, et al: CD45-cross-linking stimulates IFN-gamma production in NK cells. J Immunol 154: 644-652, 1995.

33. Dawes R, Petrova S, Liu Z, et al: Combinations of CD45 isoforms are crucial for immune function and disease. J Immunol 176: 3417-3425, 2006.

34. Takahashi H, Tsuji H, Hashimoto Y, Ishida-Yamamoto A and Iizuka H: Serum cytokines and growth factor levels in Japanese patients with psoriasis. Clin Exp Dermatol 35: 645-649, 2010.

35. Szegedi A, Aleksza M, Gonda A, et al: Elevated rate of Thelper1 $(\mathrm{T}(\mathrm{H}) 1)$ lymphocytes and serum IFN-gamma levels in psoriatic patients. Immunol Lett 86: 277-280, 2003.

36. Ozer Arican, Murat Aral, Sezai Sasmaz, et al: Serum levels of TNF-alpha, IFN-gamma, IL-6, IL-8, IL-12, IL-17, and IL-18 in patients with active psoriasis and correlation with disease severity. Mediators Inflamm 24: 273-279, 2005.

37. Zhang K, Zhang R, Li X, et al: Promoter methylation status of p15 and p21 genes in HPP-CFCs of bone marrow of patients with psoriasis. Eur J Dermatol 9: 141-146, 2009.

38. Yin G, Li J, Wan Y, et al: Abnormality of RUNX1 signal transduction in psoriatic CD34+ bone marrow cells. Br J Dermatol 164: 1043-1051, 2011. 